\title{
LARGe-AMPlitude Motion In POLYMER CRYsTALS AND MESOPHASES
}

Bernhard Wunderlich

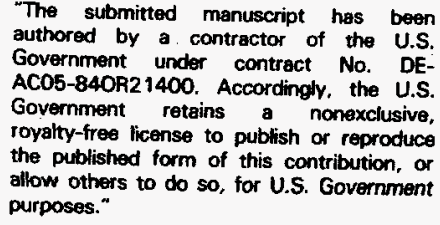

Department of Chemistry, The University of Tennessee, Knoxville, TN 37996-1600, and Chemical and Analytical Sciences Division, Oak Ridge National Laboratory, Oak Ridge, TN 37831-6197, USA

Abstract: Large-amplitude motion of macromolecules involves mainly rotation 9 about bonds (conformational motion). In the liquid phases, the large-amplitude motion is coupled with disorder and accounts for the flow and viscoelastic behavior. Perfectly ordered crystals, in contrast, permit only little large-amplitude motion. The mesophases are intermediate in order and mobility. In crystals, largeamplitude motion leads initially to gauche defects and kinks (conformational defects), and ultimately may produce conformationally disordered crystals (condis crystals). Molecular dynamics simulations of crystals with up to 30,000 atoms have been carried out and show the mechanism of defect formation, permit the study of the distribution of defects, and the visualization of hexagonal crystals. The distinction between main-chain liquid-crystalline macromolecules and condis crystals, the two mesophases of polymers, can be done on the basis of an analysis of the phase separation (partial crystallinity), present in condis crystals and not in liquid crystals. Solid state NMR is the tool of choice for the detection of mobile and rigid phases. In highly drawn fibers one can find four different states of order and mobility. Besides the (defect) crystalline phase and the isotropic amorphous phase, an intermediate oriented phase and a rigid amorphous phase exists.

\section{INTRODUCTION}

In the past, most effort in understanding crystals of macromolecules involved the study of the molecular structure [1]. The magnification of the length scale from the microscopic dimension of nanometers to the macroscopically recognizable micrometer scale is only $10^{3}$. More recently, it became increasingly important to study the atomic time scale of motion which is in the picosecond range, compared to the macroscopic time scale of milliseconds. Such slow-motion presentation can only be accomplished by computers and involves magnification by a factor of $10^{9}$ ! [2]. This lecture will be about the study of both these 
magnifications and the linkage of microscopic defects and motion with macroscopic appearance and mechanical properties.

\section{COMPUTER SIMULATION OF DEFECTS AND LARGE-AMPLITUDE MOTION}

The basic model used for crystal simulations consists of a cluster of 7 to 192 of all-transchains of $\mathrm{C}_{100} \mathrm{H}_{200}$ or $\mathrm{C}_{50} \mathrm{H}_{100}$, i.e. of a crystal length of 25 or $12.5 \mathrm{~nm}$, respectively. The chains are initially placed on positions determined by the orthorhombic or monoclinic polyethylene crystal structures (ORTH: $a=0.74, b=0.49, c=0.25 \mathrm{~nm}$, with $c$ being the chain axis; MONO: $a=0.81, b=0.25, c=0.48 \mathrm{~nm}$, and $\beta=108^{\circ}$, with $b$ being the chain axis). The chain axes are chosen to be parallel to $z$ in the Cartesian coordinates, as shown in Fig. 1 for two polymorphs of 192 chains.

The simulations used both, united-atom (UA) and full-atom (FA) models. In the UA simulation a $\mathrm{CH}_{2}$ group is represented by a single center of mass 14.03 , in the FA simulation, all atoms are accounted for.

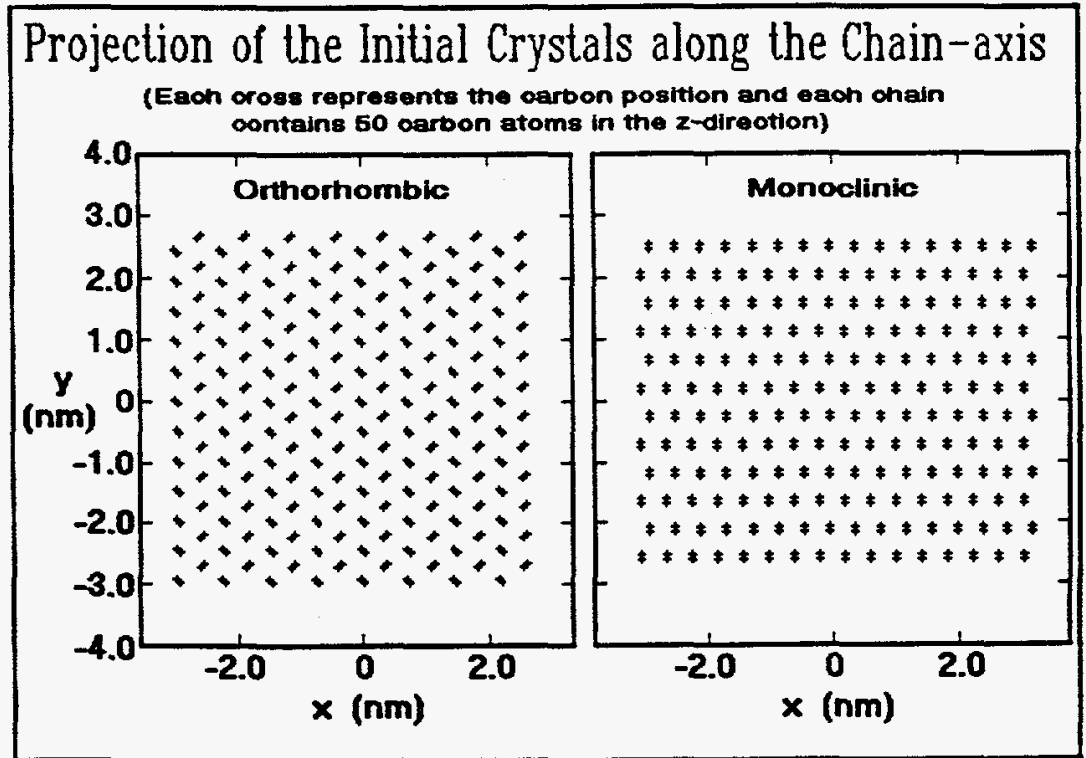

Figure 1

Stretching, bending, and torsion were considered. All atoms contributed to the nonbonding interactions (van der Waals, weak interactions) and were cut-off at $1.0 \mathrm{~nm}$ in the neighbor list generated during the simulation. For the UA model, we used the commonly accepted force-field parameters [3]. For the FA model, the parameters of Barnes and Fanconi [4] were employed, as is described in detail in [5]. The advanced programming strategies for our MD codes permit these large simulations to be carried to times as long as 100 ps. The details have been given in [6]. To start the simulation, a certain amount of momentum, selected by a random number generator, was distributed among all atoms. The velocities of the atoms reached a Boltzmann distribution within about 0.2 ps. The trajectories were typically calculated every $0.05 \mathrm{ps}$ for UA simulations and 0.01 ps for FA simulations, using an ordinary differential equation solver. If the torsion angle about the backbone bond deviated from that of the all-trans conformation 
by more than $90^{\circ}$, it was considered to be a gauche bond. The concentration of gauche bonds was then extracted from the trajectories. The life-time of most gauche bonds was less than $10 \mathrm{ps}$ and the gauche concentration fluctuated with time. The simulations were

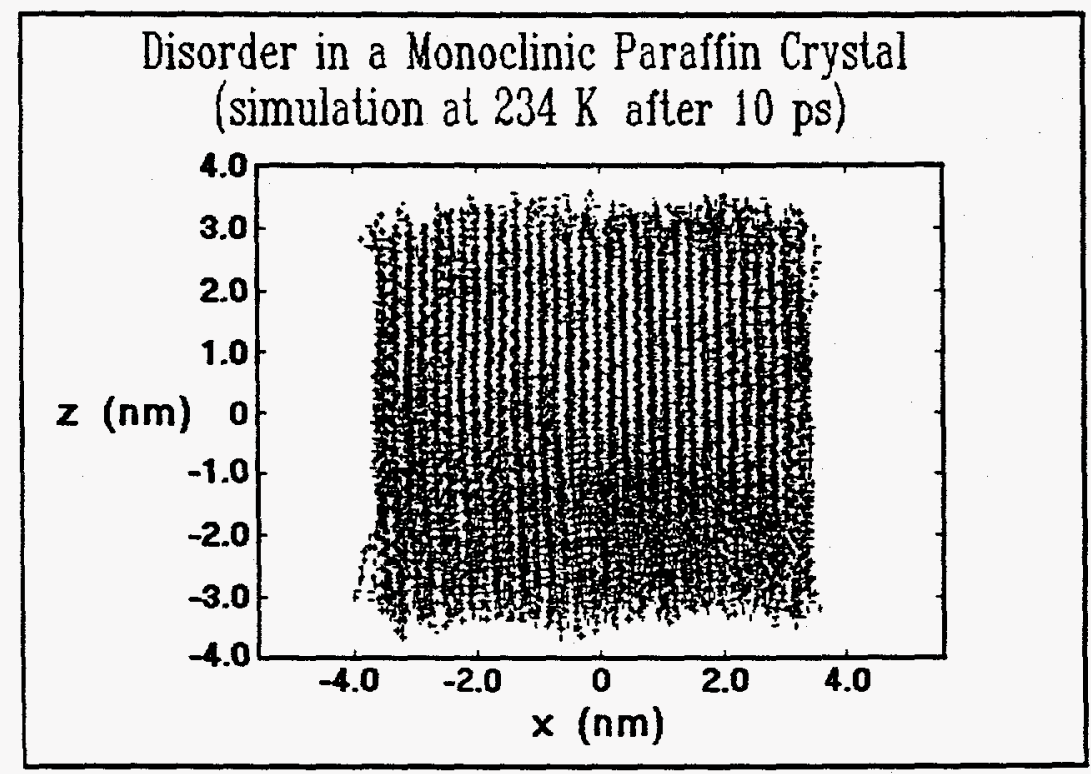

Figure 2 carried out on the Cray XMP at Oak Ridge National Laboratory and the IBM 3090 and VAX 9000 at the University of Tennessee at Knoxville, requiring overall several thousand hours of CPU time. A typical sideview of a crystal is given in Fig. 2. Even at such a low temperature, the deviations of the all-trans-chains from their initial positions are

substantial, and increase as one approaches the surface of the crystal. Furthermore, a considerable roughness exists on the crystal surfaces, including longitudinal displacements of the chains as a whole.

During the course of the simulation, the gauche-concentration reaches an initial steady state after about 5-10 ps. At longer simulations times, the temperature of the crystal drops due to energy losses caused by limits in the computation precision. As a result, gauche concentrations decrease. This change is only $1-3$ kelvins per picosecond, so that the attained steady state is kept for the full simulation range and a large number of data can be extracted, as is shown in Fig. 3 for MONO crystals as well as constrained and full atom simulations [7]. A number of experimental gaucheconcentrations gained by IR

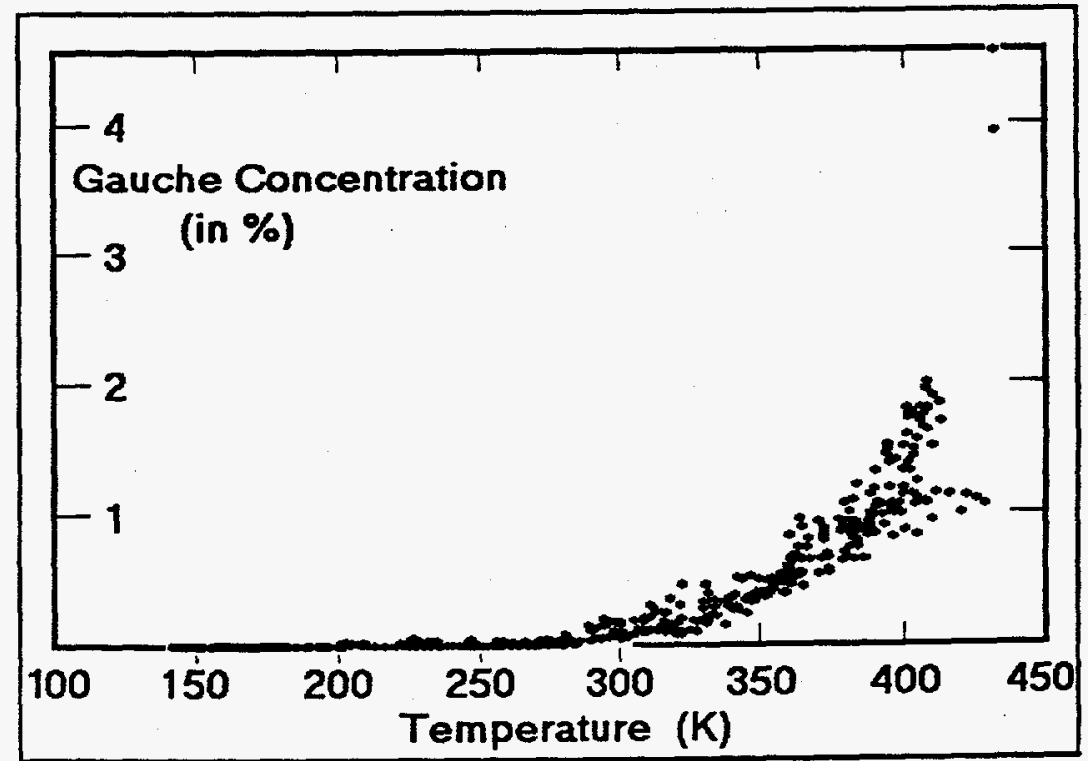

Figure 3 
measurements [8] and derived from the increase in heat capacity beyond the limits established for the vibrational contributions [9] agree with the data of Fig. 3. Although the absolute concentration of gauche conformations is small, the rate of their formation is high because of their short life-time [10], as shown in Fig. 4, where the rate of change

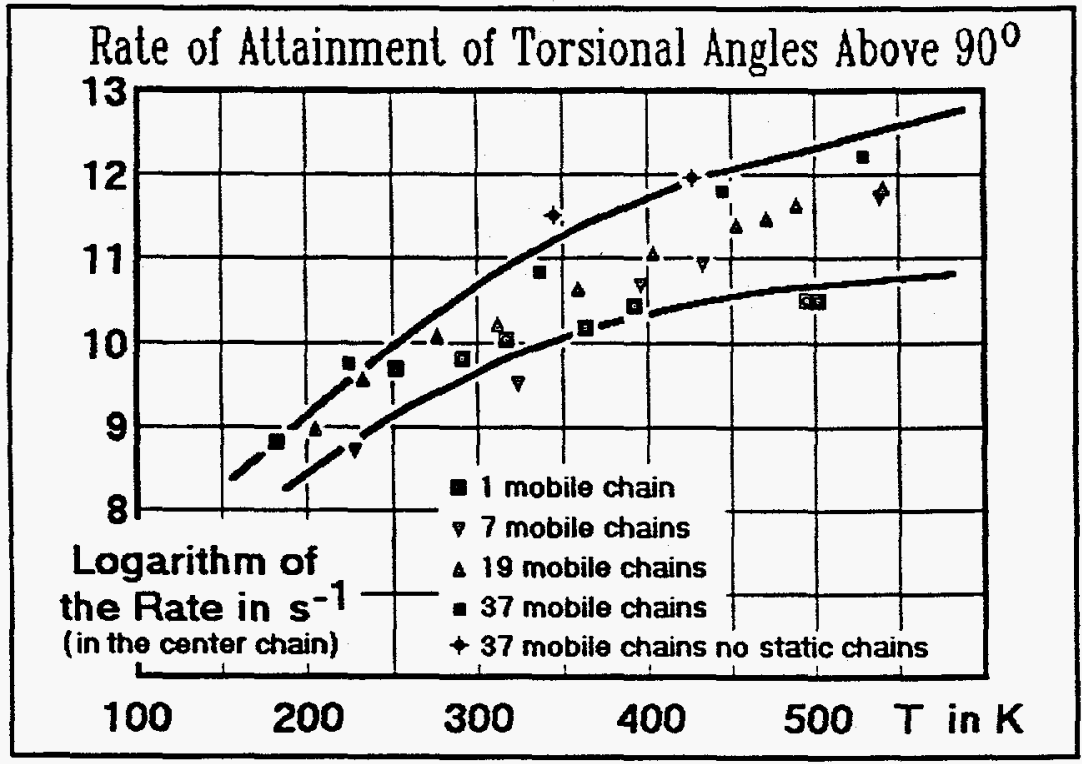

Figure 4

of a trans- to a gauche-bond is given for computations with different numbers of chains that were simulated at either constant volume or pressure [10]. This large number of point defects, produced over a macroscopically short time interval in the polymer crystal is now linked to the deformation mechanisms [11]. All the conformational defects are generated as a result of interactive thermal motion, involving a combination of transverse, torsional, and longitudinal skeletal vibrations. The conformational defects were found to be relatively immobile, but initiate the longitudinal diffusion of the chain in the crystal when small forces are applied, as shown in Fig. 5 [12]. The longitudinal acoustic mode, visible in the figure, could be directly linked with the step-wise diffusion through the crystal [11]. The torsional motion is illustrated in simulations

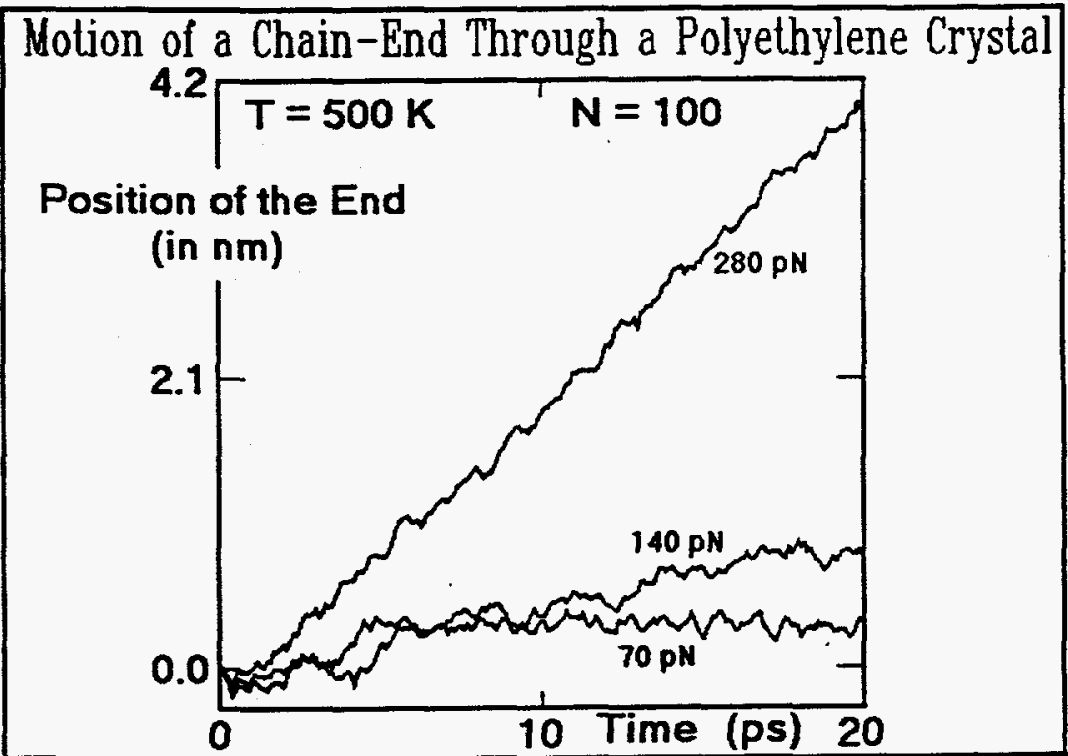

Figure 5 of the hexagonal phase, frequently found in polymers and paraffins. Figure 6 illustrates the time dependence of

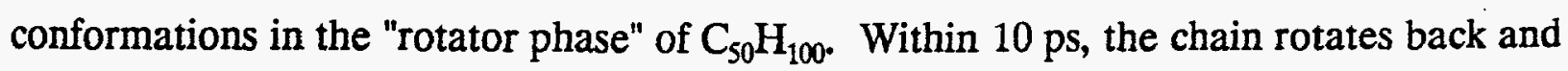
forth by about $90^{\circ}$. 


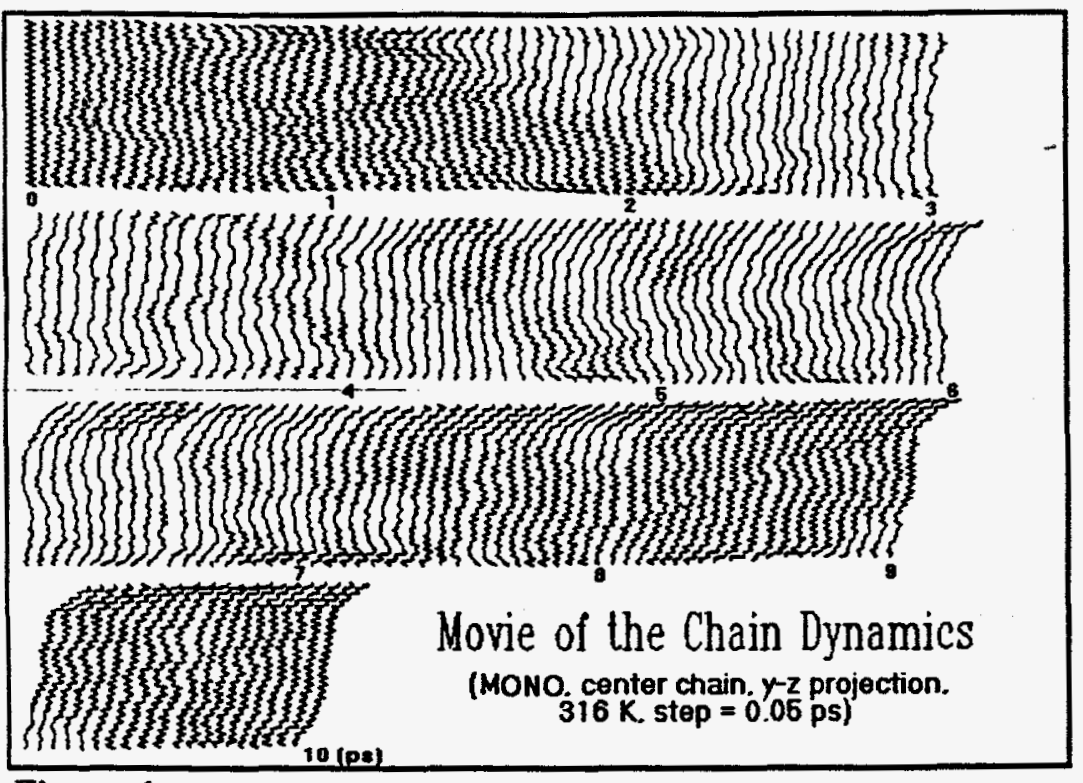

Figure 6
Besides formation of conformational defects, twisting of the chain, and longitudinal diffusion, it could also be shown that lateral motion of the chains is possible by larger external forces. This mechanism is illustrated in Fig. 7 [7]. It involves now slip planes and edge dislocations as known from rigid motifs. In rigid

polymers these were studied by Martin [13]. The deformation of the crystal in Fig. 7 was accomplished by placing the chains into a rigid, three-sided enclosure under a pressure of 250-500 $\mathrm{MPa}$, forcing the chains to move laterally. The deformation starts at 2 ps with a buckling of the $x-z$ surface and has reached completion at 8 ps.

Up to now all the discussed crystals are still "defect crystals," i.e. their total number of defects does remain small (up to about $1-2 \%$ ) and their long-range order can be detected by X-

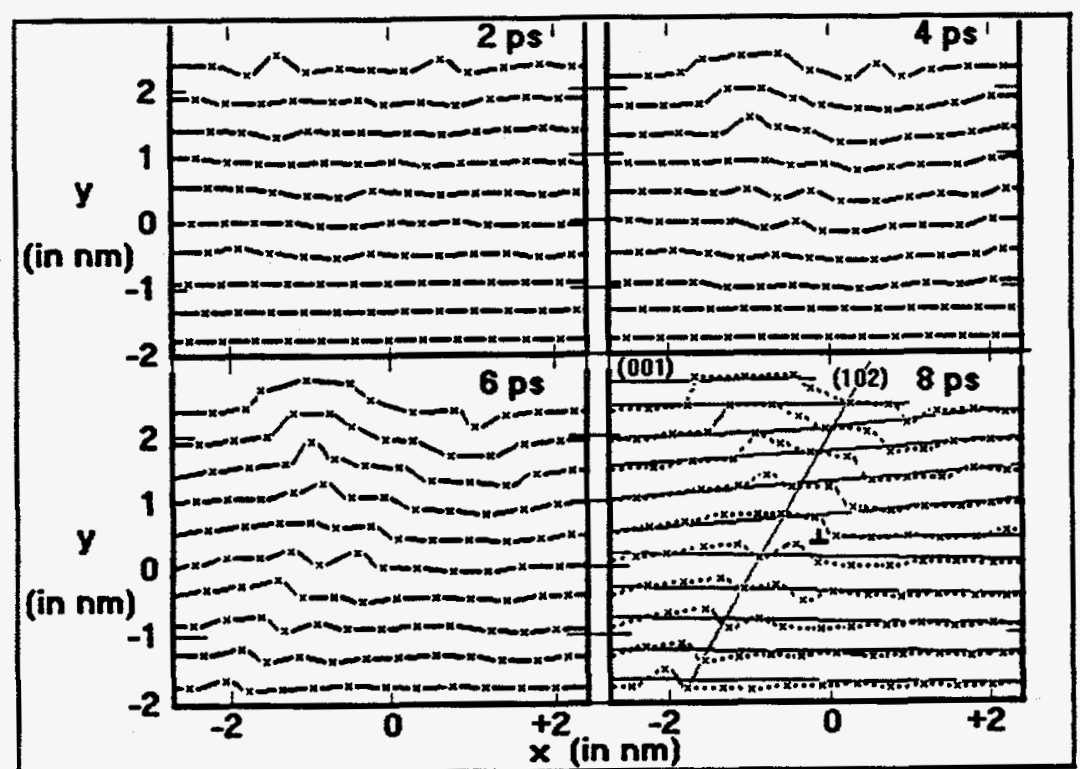

Figure 7

ray diffraction. At higher temperatures, some polymers develop stable mesophases with large disorder and mobility. These mesophases will be discussed next.

\section{MESOPHASES}

Linear macromolecules show very little translational and orientational motion of the molecule as a whole. Once positionally and orientationally ordered, they may keep this order in the form of mesophases (intermediate phases). Liquid crystals can be defined 
as partially orientationally ordered liquids [14]. Of the $20-50 \mathrm{~J} /(\mathrm{K} \mathrm{mol})$ total entropy of orientational ordering, normally found on crystallization of a rigid motif [1], the mesogen in low-molar-mass nematic, thermotropic liquid crystals orders only in the amount of 1-5 $\mathrm{J} /(\mathrm{K} \mathrm{mol})$ (entropy of isotropization). The translational motion of the mesogen and all large-amplitude motion of the flexible parts of the liquid crystalline molecule are close to liquid-like, justifying the name chosen for this phase.

Macromolecular, main-chain liquid crystals have their mesogens separated by flexible sequences of $\mathrm{CH}_{2}$ - and $\mathrm{O}$-groups which permit an orientational ordering of the mesogens with a reasonable degree of translational freedom. The flexible sequences are not, however, fully independent of the orientation of the mesogen. To connect the orientationally aligned mesogens, the flexible sequences order themselves to a small degree [total entropy of isotropization $15.6 \pm 7.3 \mathrm{~J} /(\mathrm{K} \mathrm{mol})$, average of 64 polymers (14)]. That some of the additional entropy comes from the connecting flexible portions of the

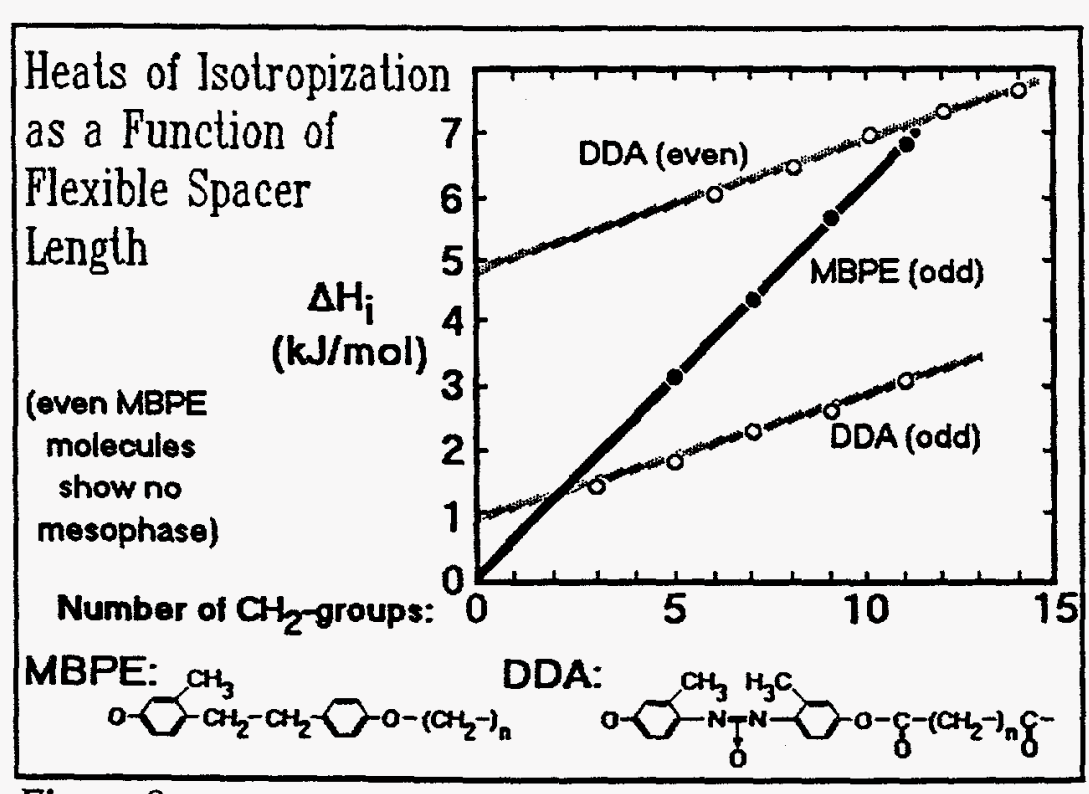

Figure 8 chain is seen in Fig. 8 [15]. From heats of isotropization one can derive an average contribution to the entropy of isotropization per methylene group of $1.9,0.87$, and $0.57 \mathrm{~J} /(\mathrm{K} \mathrm{mol})$, much less than full conformational ordering that needs a $\Delta S$ of $7-12 \mathrm{~J} /(\mathrm{K} \mathrm{mol})$ per fully ordered bond (1). Note also, that in the case of MBPE almost all stability of

the liquid crystalline phase arises from the flexible segment at the lower isotropization temperature ( $T_{i} \approx 346 \mathrm{~K}$, MBPE-9, monotropic). The DDA-10 has a $T_{i}$ of about $420 \mathrm{~K}$.

At lower temperature, the liquid crystals gain additional order in a crystallization process that requires, in contrast to the liquid crystal formation, a substantial supercooling. For polymeric liquid crystals, the homogeneous phase separates during this process into two phases. In most cases, although the additional ordering is substantial $[\approx 90 \mathrm{~J} /(\mathrm{K} \mathrm{mol})$ in MBPE-9 for the ordered phase (16)], it does not reach the expected entropy-decrease to a fully ordered crystal $\left[\Delta \mathrm{S}_{\text {fusion }} \approx 140 \mathrm{~J} /(\mathrm{K}\right.$ mol $\left.)\right]$. The ordered phase remains conformationally disordered, i.e. it is a condis crystal. Figure 9 illustrates the thermal 
behavior of the two-phase structure of MBPE-9 [16]. One phase shows a clear glass transition, the other a heat of transition, typical of a condis crystal. A certain amount of rigid-amorphous material indicates that the condis crystals are similar to fully ordered crystals.

They may not even need a mesogen, as illustrated for

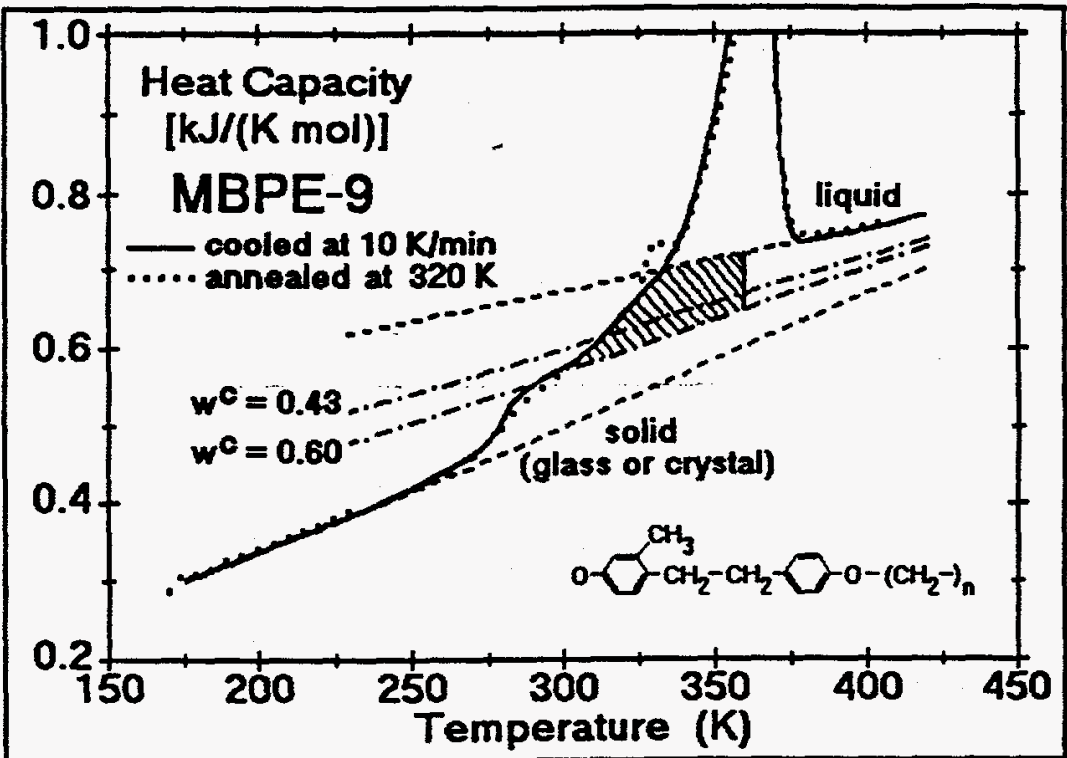

Figure 9 example, by the condis phases of polyethylene, polytetrafluoroethylene, and trans-1,4polybutadiene. The conformational disorder may, in turn, be complete or partial. The latter is the case in MBPE-9.

\begin{tabular}{|c|c|c|}
\hline $\begin{array}{l}\text { Characteris } \\
\text { Liquid Crystals }\end{array}$ & Plastic Crystals & $\begin{array}{l}\text { esophases } \\
\text { Condis Crystals }\end{array}$ \\
\hline $\begin{array}{l}\text { 1. "liquid" } \\
\text { 2. biretringence } \\
\text { 3. small } \Delta S_{i} \\
\text { often } 2-5 \mathrm{~J} /(\mathrm{K} \text { mol) } \\
\text { 4. } 100 \% \text { crystalline } \\
\text { 5. small and large mols. } \\
\text { 6. no positional order } \\
\text { some orientational } \\
\text { order } \\
\text { 7. full coniormational } \\
\text { disorder (as in melt) } \\
\text { 8. mesogen shape } \\
\text { rod or dise }\end{array}$ & $\begin{array}{l}\text { 1. "plastic" } \\
\text { 2. no biretringence } \\
\text { 3. fixed } \Delta S_{\mathrm{i}} \\
7-14 \mathrm{~J}(\mathrm{~K} \text { mol) } \\
\text { 4. } 100 \% \text { crystalline } \\
\text { 5. small molecules only } \\
\text { 6. positional order } \\
\text { no orientational } \\
\text { order } \\
\text { 7. full contormational } \\
\text { disorder (similar to } \\
\text { melt) } \\
\text { 8. mesogen shape } \\
\text { close to spherical }\end{array}$ & $\begin{array}{l}\text { 1. "solid" } \\
\text { 2. birefringence } \\
\text { 3. large } \Delta S_{i} \\
n \times[7-12 J /(K \text { mol)] } \\
\text { 4. limited crystallinity for } \\
\text { 5. macromolecules } \\
\text { 6. positional order } \\
\text { orientational order } \\
\text { 7. partial or full conior- } \\
\text { mational disorder } \\
\text { rotational isomers } \\
\text { 8. that keep the chains } \\
\text { largely parallel }\end{array}$ \\
\hline
\end{tabular}

Figure 10

The condis crystal differs from a liquid crystal by showing no positional and orientational disorder in the mesogen [17]. The differences between condis crystals and the two other mesophases are summarized in Fig. 10.

Using solid state NMR, it was possible to find that in MBPE-9 four flexible bonds were fixed in the trans-conformation (the $\mathrm{O}-\mathrm{C}$ - bonds and the $\mathrm{C}-\mathrm{C}$ two bonds removed from $\mathrm{O}-\mathrm{C}$ ) and all others kept their liquid-like disorder and mobility [18]. Poly(oxy-1,4-phenylene-oxyxylylene-oxy-1-4-phenylene-oxy-undecamethylene), as another example of a similar condis crystal former showed two polymorphs with different numbers of flexible bonds fixed in the trans-conformation (2/3 and 1/3) [19]. The condis phases could in all cases be clearly separated from the liquid because of their restricted mobility. The methods to identify 
liquid crystals and condis crystals by NMR were developed using low molecular-mass model-compounds that show no complications due to partial crystallinity [20].

The additional heat capacity contribution below the melting temperature in Fig. 9 (shaded area) illustrates typical increase in order on cooling of an initially liquid-like phase. As the temperature decreases, this ordering freezes and the flexible parts of the crystal assume a glass-like state without large-amplitude motion [CD-glass [17]. The approximate remaining entropy of each disordered bond is that of amorphous polyethylene at $0 \mathrm{~K}[\approx 3 \mathrm{~J} /(\mathrm{K} \mathrm{mol})]$. Some examples of condis glasses are discussed in the final part of this presentation.

\section{METASTABLE MESOPHASES}

A well-known, metastable, frozen-in mesophase (CD-glass) is exhibited by polypropylene crystallized below $350 \mathrm{~K}[14,17]$. This phase was first described in 1959 as smecticmesomorphic [22]. The phase assignment was made based on X-ray diffraction, as illustrated in Fig. 11 [14]. The crystallinity of this polymer is about $40 \%$ at room temperature, but the chains within the crystals have many conformational defects in the form of helix reversals (see [17]). As the temperature is increased, the frozen defects become

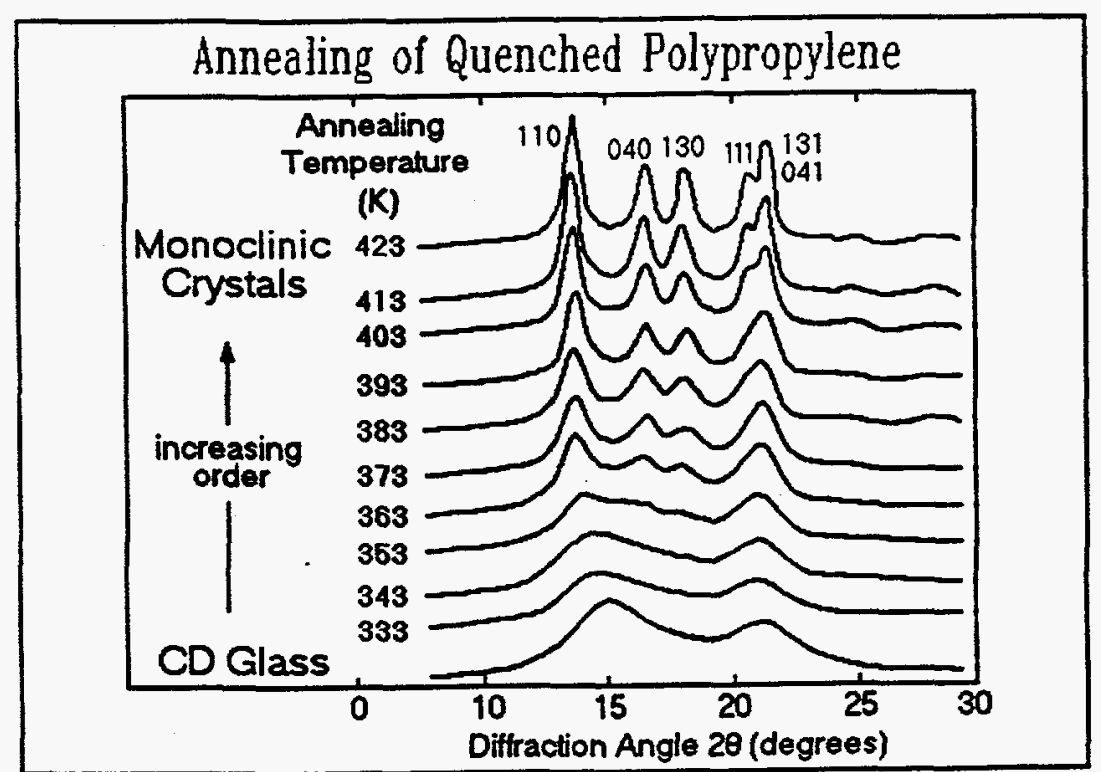

Figure 11

mobile at about $330 \mathrm{~K}$ with an exotherm of about $600 \mathrm{~J} / \mathrm{mol}$ [23]. One expects thus the glass transition of the condis crystal to be also at about this temperature. Because of the metastability of the phase, immediate reorganization takes place to the more ordered monoclinic phase [decrease in entropy estimated to be about $2 \mathrm{~J} /(\mathrm{K} \mathrm{mol})$ ]. No temperature and pressure conditions have been found at which this condis phase is stable. The condis phase of polypropylene must thus be an intermediate in the crystallization (Ostwald's rule of stages [1]). 
Another example of a metastable mesophase is the Intermediate phase found in drawn fibers. The polymer to be discussed is poly(ethyleneterephthalate), PET [24-26].

Figure 12 illustrates the X-ray fiber diffraction pattern for a drawn sample, corrected for absorption, Compton scattering, and polarization. A full pattern (Rietveld) analysis of the pattern was carried out, considering atomicpositions, unit cell, temperature and scale factors; the crystal orientation, anisotropic size, and misorientation; and the paracrystallinity matrix [24]. The resulting, calculated crystalline diffraction is shown in Fig. 13. Trying to subtract the pattern of Fig. 13 from Fig. 12 does not lead, however, to an amorphous structure as shown in Fig. 14 and expected from the usual two-phase model of a semicrystalline polymer [25]. An additional, third component is necessary to generate a fiber diffraction pattern as in Fig. 12, the

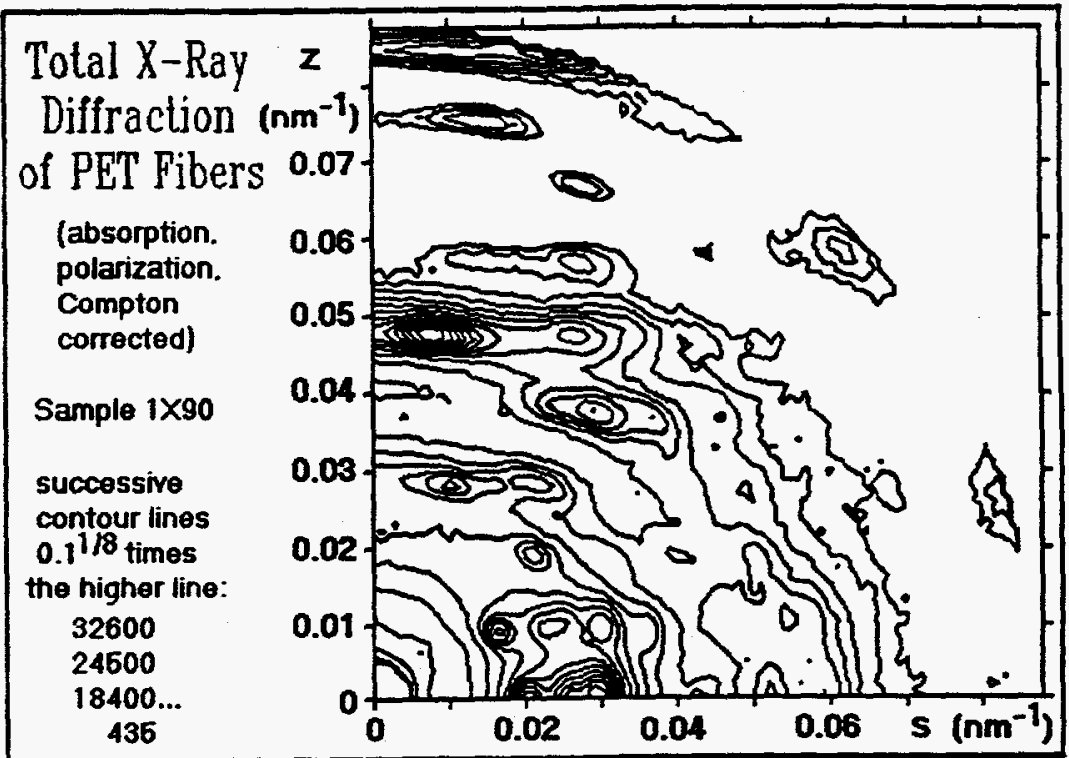

Figure 12

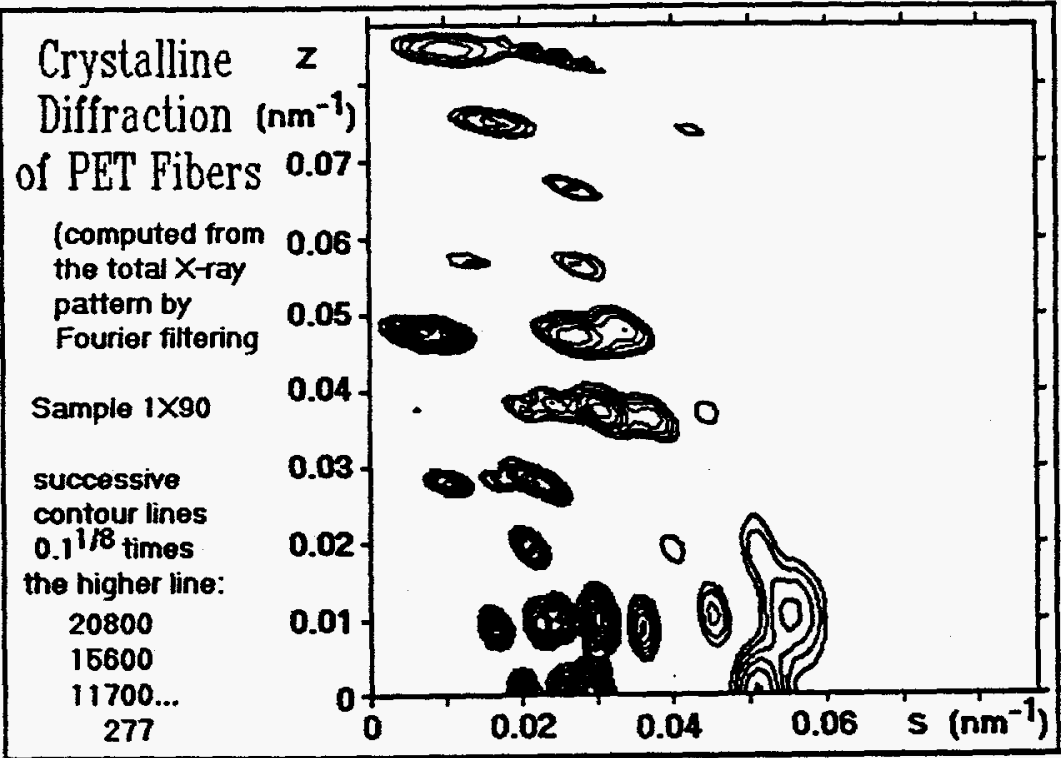

Figure 13

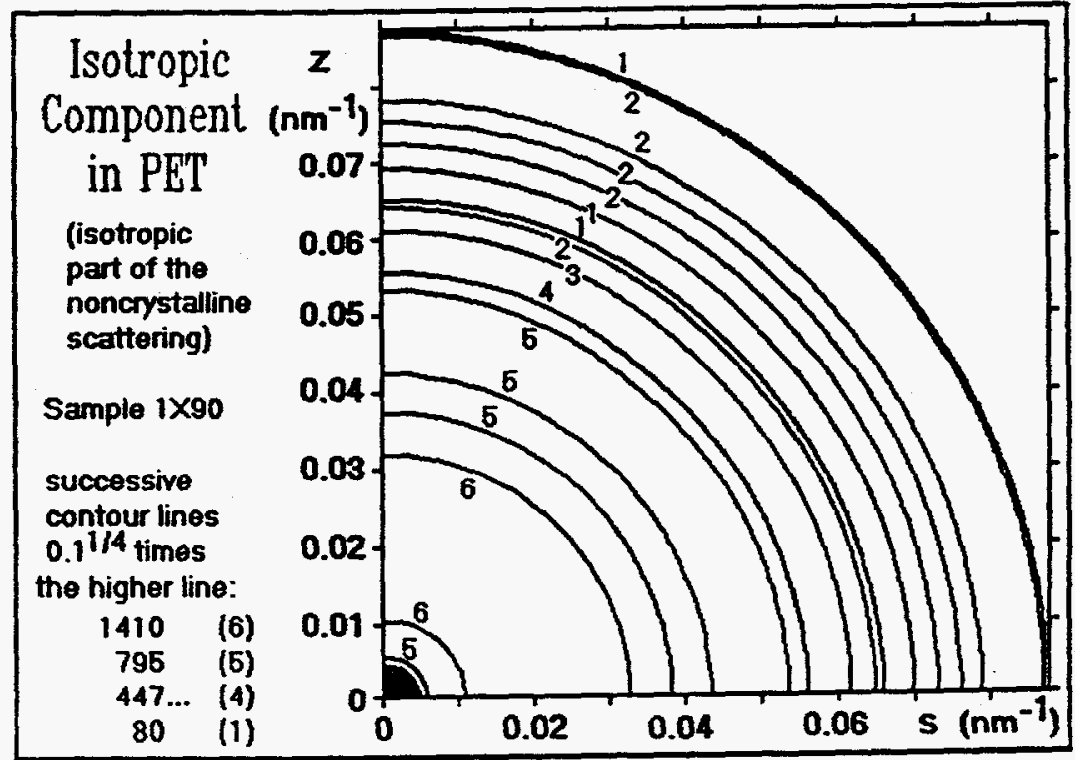

Figure 14 
intermediate, oriented phase. Figure 15 illustrates the X-ray scattering expected from the new phase. An approximate $22.9 \%$ of crystals, as shown in Fig. 13, $42.2 \%$ isotropic, amorphous material, as is shown in Fig. 14, and 35.7\% of the third phase of Fig. 15 make up the original Fig. 12. The new phase, called oriented, intermediate, is quite similar to the prior observed "mesomorphic" phase that appears as an early stage on annealing of slowly drawn PET fibers at temperatures up to the glass transition temperature [27].

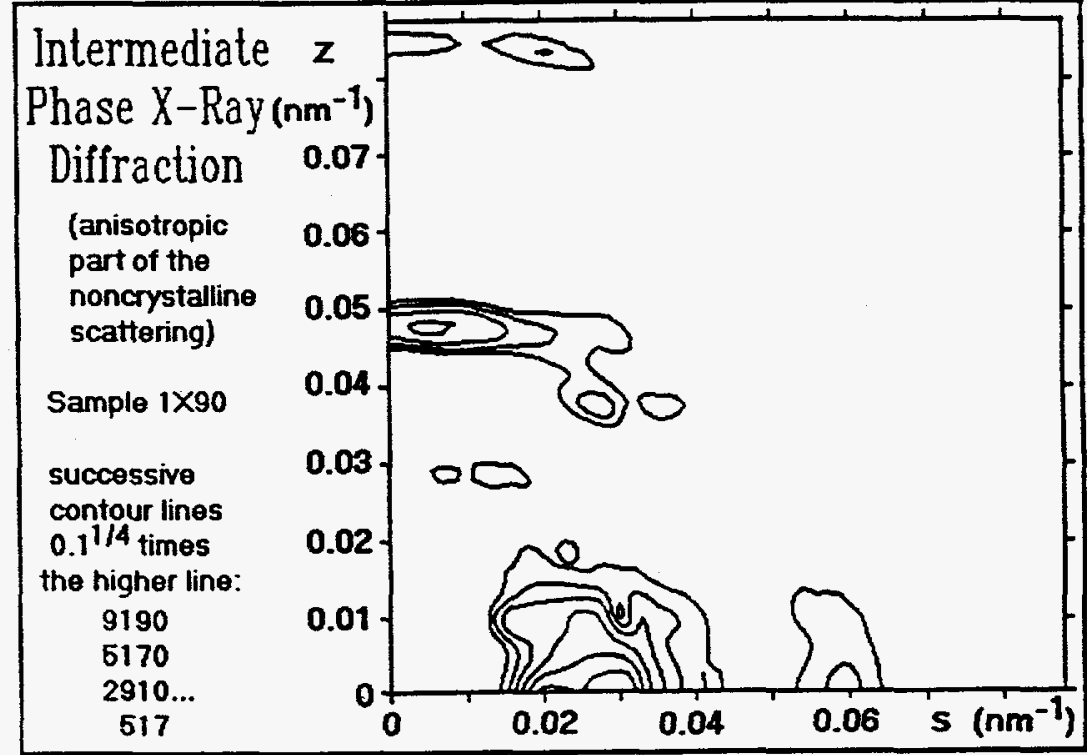

Figure 15

At higher temperature, the normal, triclinic crystal structure is generated from the mesophase, which ultimately disappears completely. In the present framework, the diffraction pattern of Fig. 15 is characterized as a metastable $\mathrm{CD}$ glass.

The third phase in PET fibers permitted to develop correlations of its amount and orientation to structure-insensitive properties, such as the modulus [26]. The presence of crystalline and amorphous content in the analyzed PET fibers was of little importance, except for their role in creating the intermediate phase. Even the more structure sensitive tenacity could be correlated to the structure of the intermediate phase [26].

A similar intermediate phase could also be identified for polyethylene and it is likely that this type of structure is, with changes for individual polymers, quite general in drawn fibers and films of polymers [28]. The evolving knowledge about large-amplitude motion in partially ordered, flexible polymers may even lead to a detailed understanding of the catastrophic changes that occur during macroscopic deformation, and permit us to make progress towards optimizing these processes and designing new fabrication methods.

\section{CONCLUSIONS}

Large-amplitude motion in a crystal with a molecular time scale of picoseconds is involved in defect formation, chain diffusion, and plastic deformation in crystals. The mesophases 
of flexible macromolecules, ranging from liquid crystals to condis crystals, can be understood based on the amount of conformational disorder and mobility. The condis crystals may cover a much larger class of polymers than thought before. Their properties are only beginning to be understood (chain extension on annealing, ease of plastic deformation, and freezing to the metastable $\mathrm{CD}$ glass). Quenching during crystallization or drawing may produce $\mathrm{CD}$ glasses. Their properties may finally permit to link the cycle: production, structure analysis, and performance.

ACKNOWLEDGEMENT: This work was supported by the Division of Materials Research, the National Science Foundation, Polymers Program, Grant \# DMR 90-00520 and the Division of Materials Sciences, Office of Basic Energy Sciences, U.S. Department of Energy, Contract DE-AC05-84OR21400 with Martin Marietta Energy Systems, Inc.

\section{REFERENCES}

[1] B. Wunderlich, "Macromolecular Physics; Vol. 1, Crystal Structure, Morphology, Defects; Vol. 2, Crystal Nucleation, Growth, Annealing; Vol. 3, Crystal Melting." Academic Press, New York, NY, 1973, 1976, 1980.

[2] B. G. Sumpter, D. W. Noid, and B. Wunderlich, "Atomistic Dynamics of Macromolecular Crystals." Springer Verlag, Berlin, to be published 1994. (Adv. Polymer Sci, Vol. on "Atomistic Modelling of Physical Properties of Polymers.")

[3] G. L. Liang, D. W. Noid, B. G. Sumpter, and B. Wunderlich, Makromol. Chem., Theory Simul. 2, 245 (1993); Acta Polymerica., 44, 219 (1993); J. Polym. Sci.: Part B: Polym. Phys. 31, 1909 (1993).

[4] J. Barnes, and B. Fanconi, J. Phys. Chem. Ref. Data, 7, 1309 (1978).

[5] G. L. Liang, D. W. Noid, B. G. Sumpter, and B. Wunderlich, Comp. Polym. Sci. 3, 101 (1993).

[6] D. W. Noid, B. G. Sumpter, B. Wunderlich, and G. A. Pfeffer, J. Comp. Chem. 11, 236 (1990); D. W. Noid, B. G. Sumpter, and R. L. Cox, J. Comp. Polym. Sci. 1, 161 (1991).

[7] G. L. Liang, D, W. Noid, B. G. Sumpter, and B. Wunderlich, J. Phys. Chem, Accepted for publication (1994).

[8] R. G. Snyder, M. Maroncelli, S. P. Qi, and H. L. Strauss, Science 214, 188 (1981);

M. Maroncelli, H. L. Strauss, and R. G. Snyder, J. Chem. Phys. 82, 2811 (1985); Y. Kim, H. L. Strauss, and R. G. Snyder, J. Phys. Chem. 93, 7520 (1989). 
[9] D. W. Noid, B. G. Sumpter, M. Varma-Nair, and B. Wunderlich, Makromolekulare Chemie, Rapid Commun, 10, 377 (1989).

[10] B. G. Sumpter, D. W. Noid, and B. Wunderlich, J. Chem. Phys., 93, 6875 (1990).

[11] B. G. Sumpter, D. W. Noid, and B. Wunderlich, Macromolecules, 25, 7247 (1992).

[12] D. W. Noid, B. G. Sumpter, and B. Wunderlich, Polymer Communications, 31, 304 (1990).

[13] D. C. Martin, Trends in Polymer Science, 1, 178 (1993).

[14] B. Wunderlich and J. Grebowicz, Adv. Polymer Sci, 60/61, 1 (1984).

[15] M. A. Yandrasits, S. Z. D. Cheng, A. Zhang, J. Cheng, B. Wunderlich, and V. Percec, Macromolecules, 25, 2112 (1992).

[16] Y. Jin, J. Cheng, B. Wunderlich, S. Z. D. Cheng, M. A. Yandrasits, and A. Zhang, Polymers for Advanced Technology (1994).

[17] B. Wunderlich, M. Möller, J. Grebowicz, and H. Baur, "Conformational Motion and Disorder in Low and High Molecular Mass Crystals." Springer Verlag, Berlin, 1988, (Adv. Polymer Sci, Volume 87).

[18] J. Cheng, Y. Jin, B. Wunderlich, S. Z. D. Cheng, M. A. Yandrasits, A. Zhang, and V. Percec, Macromolecules, 25, 5991 (1992).

[19] J. Cheng, Y. Jin, W. Chen, B. Wunderlich, H. Jonsson, A. Hult, and U. W. Gedde J. Polymer Sci, Part B: Polymer Physics, 32, 721 (1994).

[20] J. Cheng, W. Chen, Y. Jin, and B. Wunderlich, Mol. Cryst. Liq. Cryst., 241, 291 (1994).

[22] G. Natta, M. Peraldo, and P. Corradini, Rend. Accad. Naz. Lincei, 24, 14 (1959).

[23] J. Grebowicz, S.-F. Lau, and B. Wunderlich, J. Polymer Sci, Symposia, 71, 19 (1984).

[24] Y. Fu, W. R. Busing, Y. Jin, K. A. Affholter and B. Wunderlich, Macromolecules, 26, 2187 (1993).

[25] Y. Fu, W. R. Busing, Y. Jin, K. A. Affholter and B. Wunderlich, Makromolekulare Chemie 195, 803-822 (1994).

[26] Y. Fu, B. Annis, A. Boller, Y. Jin, and B. Wunderlich, J. Polymer Sci, Part B: Polymer Physics, to be published (1994).

[27] R. Bonart, Kolloid Z., 210, 16 (1966); 213, 1 (1966); 231, 438 (1968).

[28] W. Chen, Y. Fu, and B. Wunderlich, J. Polymer Sci., Part B: Polymer Physics, to be published (1994). 


\section{DISCLAIMER}

This report was prepared as an account of work sponsored by an agency of the United States Government. Neither the United States Government nor any agency thereof, nor any of their employees, makes any warranty, express or implied, or assumes any legal liability or responsibility for the accuracy, completeness, or usefulness of any information, apparatus, product, or process disclosed, or represents that its use would not infringe privately owned rights. Reference herein to any specific commercial product, process, or service by trade name, trademark, manufacturer, or otherwise does not necessarily constitute or imply its endorsement, recommendation, or favoring by the United States Government or any agency thereof. The views and opinions of authors expressed herein do not necessarily state or reflect those of the United States Government or any agency thereof.

This report has been reproduced directly from the best available copy.

Available to DOE and DOE contractors from the Office of Scientific and Technical Information, 175 Oak Ridge Turnpike, Oak Ridge, TN 37831; prices available at (615) 576-8401.

Available to the public from the National Technical Information Service, U.S. Department of Commerce, 5285 Port Royal Road, Springfield, VA 22161; phone orders accepted at (703) 487-4650. 
